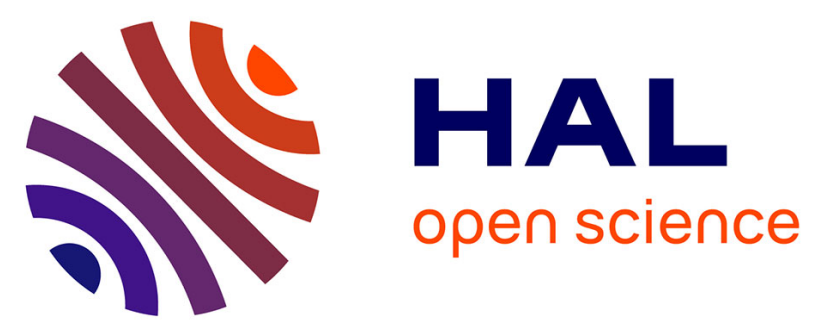

\title{
Functional characterization of hPCL3 (human Polycomb-like 3) isoforms identifies them as components of distinct EZH2 protein complexes
}

Gaylor Boulay, Claire Rosnoblet, Cateline Guérardel, Pierre-Olivier Angrand, Dominique Leprince

\section{- To cite this version:}

Gaylor Boulay, Claire Rosnoblet, Cateline Guérardel, Pierre-Olivier Angrand, Dominique Leprince. Functional characterization of hPCL3 (human Polycomb-like 3) isoforms identifies them as components of distinct EZH2 protein complexes. Biochemical Journal, 2011, 434 (2), pp.333-342. 10.1042/BJ20100944 . hal-00565902

\section{HAL Id: hal-00565902 https://hal.science/hal-00565902}

Submitted on 15 Feb 2011

HAL is a multi-disciplinary open access archive for the deposit and dissemination of scientific research documents, whether they are published or not. The documents may come from teaching and research institutions in France or abroad, or from public or private research centers.
L'archive ouverte pluridisciplinaire HAL, est destinée au dépôt et à la diffusion de documents scientifiques de niveau recherche, publiés ou non, émanant des établissements d'enseignement et de recherche français ou étrangers, des laboratoires publics ou privés. 


\title{
Functional Characterization of hPCL3 (human Polycomb-like 3) Isoforms Identifies Them as Components of Distinct EZH2 Protein Complexes.
}

\author{
Gaylor Boulay $^{1}$, Claire Rosnoblet ${ }^{2,3}$, Cateline Guérardel $^{1}$, Pierre-Olivier \\ Angrand $^{2}$ and Dominique Leprince ${ }^{1,4}$
}

Running title: Characterization of hPCL3 isoforms

Keywords: Polycomb, PRC2, Polycomb-like, hPCL3, PHF1, PHF19, Chromatin, Epigenetics.

(1) CNRS UMR 8161 «Institut de Biologie de LILLE», Université Lille Nord de France, Institut PASTEUR de LILLE, IFR 142, 1 Rue Calmette, 59017 LILLE Cedex, FRANCE.

(2) Chromatinomics, Interdisciplinary Research Institute, Université Lille Nord de France, CNRS USR 3078, Parc Scientifique de la Haute Borne, 50 Avenue HALLEY, 59658 VILLENEUVE D'ASCQ, FRANCE

(3) Present address: Unité de Glycobiologie Structurale et Fonctionnelle Université Lille Nord de France, CNRS UMR 8576, Cité Scientifique, Bât. C9, F59655 VILLENEUVE D’ASCQ, France.

(4) Correspondence : dominique.leprince@ibl.fr

\begin{abstract}
Polycomb group (PcG) proteins are conserved transcriptional repressors essential to regulate cell fate and to maintain epigenetic cellular memory. They work in concert through two main families of chromatin-modifying complexes, PRC1 and PRC2-4 (Polycomb repressive complexes). In Drosophila, PRC2 contains the H3K27 histone methyltransferase E(Z) whose trimethylation activity towards $\mathrm{PcG}$ target-genes is stimulated by Polycomb-like (PCL). Here, we have examined $h P C L 3$, one of its three human paralogues. Through alternative splicing, hPCL3 encodes a long isoform, hPCL3L containing an N-terminal TUDOR and two PHD domains and a smaller isoform, hPCL3S, lacking the second PHD finger (PHD2). By quantitative RT-PCR analyses, we showed that both isoforms are widely co-expressed at high levels in medulloblastoma. By co-immunoprecipitation analyses, we demonstrated that both isoforms interact with EZH2 through their common TUDOR domain. However, the hPCL3Lspecific PHD2 domain, which is better conserved than PHD1 in the PCL family, is also involved in this interaction and implicated in the self-association of hPCL3L. Finally, we have demonstrated that both hPCL3 isoforms are physically associated with EZH2, but in different complexes. Our results provide the first evidence that the two hPCL3 isoforms belong to different complexes and raise important questions about their relative functions, particularly in tumorigenesis.
\end{abstract}




\section{INTRODUCTION}

Polycomb Group (PcG) proteins, first identified by genetic studies in Drosophila, are required for maintaining the transcriptional silence of homeotic genes as well as many other genes essential for genomic programming and differentiation [1, 2, 3]. In Drosophila as well as in vertebrates, PcG proteins interact with each other to form multimeric chromatinassociated protein complexes. These complexes and their underlying molecular mechanisms are well conserved, although they are recruited to their target-genes through different mechanisms in flies and mammals $[4,5,6]$. Two types of PcG multi-protein complexes with distinct biochemical properties have been extensively studied, PRC1 and PRC2 [1,7]. Their coordinated action is required for the silencing of target genes. The PRC2 complex is the "writer" of the histone H3 trimethylated lysine 27 (H3K27me3) repressive epigenetic mark. H3K27me3 residues are specifically bound by the chromodomain of Polycomb (PC), a component of the PRC1 complex [1, 7]. The PRC2 catalytic subunit is the SET-domain containing protein $\mathrm{E}(\mathrm{Z})$, a specific $\mathrm{H} 3 \mathrm{~K} 27$ histone methyltransferase, but three other components, Suppressor of zeste 12 [SU(Z)12], Extra sex combs (ESC) and Nucleosome remodeling factor 55-kDa subunits (NURF55) are required for the stability and full activity of the PRC2 complex [8]. In Drosophila, in addition to the prominent 600-KDa PRC2 complex, a 1-MDa PRC2 complex containing the histone deacetylase RPD3 and Polycomb-like (PCL) has been characterized [9]. Recently, elegant genetic and biochemical studies have highlighted the functional role of Polycomb-like as a key player in PcG-mediated transcriptional repression. They demonstrated that whereas PRC2 is involved in the genomewide mono- and di-methylation of $\mathrm{H} 3 \mathrm{~K} 27, \mathrm{PCL}-\mathrm{PRC} 2$ is required for the tri-methylation of $\mathrm{H} 3 \mathrm{~K} 27$, a signal which is confined to PcG target genes [10]. These results have been further extended to PHF1, one of the three human orthologues of Drosophila PCL, [11, 12].

In mammals, three Polycomb-like paralogues have been identified: PHF1 (PHD finger protein 1) also called hPCL1 (human Polycomb-like 1) [13] or Tctex3 in mice [14]; MTF2 (Metal response element binding transcription factor 2) also called hPCL2 [13, 15, 16] and hPCL3 also called PHF19 [17]. These three genes are differentially expressed suggesting that their expression pattern could provide other potential regulatory mechanisms to PcG target genes. Indeed, PHF1 and $h P C L 3$ are widely expressed in different normal tissues with some examples of co-expression $[13,16,17] . h P C L 3$ is also up-regulated in many cancers [17]. By contrast, microarray analyses in mice have demonstrated that $P c l 2$ is highly expressed in undifferentiated ESCs (Embryonic Stem Cells) and during embryonic development as well as in some adult tissues [16]. PHF1, hPCL2 and hPCL3 are highly similar and display strong sequence similarities to Drosophila PCL. In particular, they share an N-terminal module consisting of three well-defined functional domains, namely a TUDOR domain and two adjacent PHD (Plant HomeoDomain) fingers immediately followed by a domain of extended homology (EH) with Drosophila PCL (Figure 1) [17]. Finally, their C-terminal ends are highly divergent except for a common C-terminal "Chromo-like domain" weakly homologous to the chromo domain found in many chromatin-associated proteins (Figure 1) [17].

hPCL3 presents unique features in the Polycomb-like gene family. Due to different polyadenylation sites and alternative splicing mechanisms in its coding exon 5 , this gene encodes two distinct isoforms; a long isoform (580 AA), called hPCL3L, which is similar to PHF1 and hPCL2/MTF2 and a shorter isoform (207 AA) called hPCL3S which contains only the N-terminal TUDOR domain and PHD1, the first of the two PHD fingers (Figure 1) [17].

In this report, we have investigated in detail the functional properties of the two hPCL3 isoforms. By quantitative RT-PCR analyses, we demonstrate that both hPCL3 isoforms are widely co-expressed, albeit at various levels, in different normal or transformed 
cells. By transient transfection assays, we show that both the hPCL3L and hPCL3S isoforms can co-immunoprecipitate EZH2 and EED and that the small isoform interacts less efficiently than the full-length hPCL3L protein. In addition, using an antibody specific for the full-length hPCL3L protein, we demonstrate that endogenous hPCL3L proteins interact with EZH2, the catalytic component of PCR2 and EED. Through the use of various deletion constructs, we show that the shared TUDOR domain and the PHD2 domain specific for the long isoform are both involved in the interaction with EZH2. Thus, the presence of two EZH2 interacting domains (TUDOR and PHD2) in hPCL3L compared with only the TUDOR domain in hPCL3S might explain the stronger interaction observed with hPCL3L. In addition, we show that hPCL3L can self-associate in vivo through the PHD2 domain which, in contrast with PHD1, is phylogenetically well conserved in PCL3 proteins and more generally among all other Polycomb-like homologues. In close agreement with all of these results, hPCL3L and hPCL3S exhibit strikingly distinct sub-cellular localization upon immunofluorescence analyses and cell fractionation of transfected cells. Finally, gel filtration analyses demonstrate that the two hPCL3 isoforms are found in two multiprotein complexes with different molecular weights; both are similar in molecular weights to other complexes also containing $\mathrm{EZH} 2$.

Taken together, our results strongly suggest that hPCL3L and hPCL3S proteins, which harbour different combinations of functional domains, could play divergent regulatory roles in PcG-mediated transcriptional repression.

\section{EXPERIMENTAL}

\section{RNA isolation, RT-PCR and Real-time PCR analyses.}

Total RNA was reverse transcribed using random primers and MultiScribe ${ }^{\mathrm{TM}}$ reverse transcriptase (Applied Biosystems). Real-time PCR analysis was performed by Power SYBR Green (Applied Biosystems) in a MX3005P fluorescence temperature cycler (Stratagene). Results were normalized with respect to 18S RNAs used as internal control [18].

\section{Cloning of full-length hPCL3L, hpCL3S and PHF1 and of hPCL3 domains.}

IMAGE clones containing the full-length hPCL3S small isoform (BC022374) and human PHF1 (AA465397) were purchased from RZPD (Berlin, Germany). The full-length hPCL3L long isoform (AL556762) was obtained from GENOSCOPE (Evry, France). Fulllength open reading frames and relevant domains were amplified by PCR and subcloned into pcDNA3-FLAG or pcDNA3-HA expression vectors using standard procedures. All constructs were verified by sequencing.

Mammalian expression vectors for Myc-EZH2 [19] and EED [20, 21] have been previously described.

For analytical gel filtration chromatography, expression vectors were generated by site-specific recombination using the GATEWAY system (Invitrogen) of PCR-amplified ORFs into TAP-tagged Moloney murine leukemia virus-based vectors as previously described [22]. Full-length open reading frames of all cDNAs were PCR amplified from cDNA clones for hPCL3S, hPCL3L or EZH2 (Mammalian Gene Collection (MGC) cDNA clones: EZH2, IMAGE: 3901250) and cloned into the GATEWAY entry vector pDONR201 (Invitrogen) and sequence verified. Entry clones were then recombined into suitable expression vectors by GATEWAY LR reactions. 


\section{Antibodies}

Commercial antibodies of the following specificity were used: FLAG from Sigma (M2 monoclonal antibody F3165); MYC Tag from Santa Cruz (rabbit polyclonal antibodies sc-789 used at a dilution 1: 5000); HA Tag from BAbCO (rabbit polyclonal for IP and mouse monoclonal for Western blot used at a dilution 1: 1000); LAMIN A/C from Santa Cruz (H-110 rabbit polyclonal antibodies sc-20681 used at a dilution 1: 1000); GAPDH from Santa Cruz (6C5 monoclonal rabbit polyclonal antibodies sc-32223 used at a dilution 1: 500). The protein A moiety of the TAP tag was revealed with a peroxidase anti-peroxidase (PAP) soluble complex antibody produced in rabbit (P1291, Sigma; used at a dilution of 1:10 000).

The monoclonal antibodies against EED (AA19) and EZH2 (AC22) were a generous gift from Kristian Helin (BRIC, Copenhagen, DK) [20, 21]. To generate rabbit antibody against hPCL3L, the EcoRI-SmaI fragment encoding the specific C-terminus of the hPCL3L isoform (AA 382-580) was cloned in frame with GST in the pGEX2TK vector. The GSThPCL3L fusion protein was expressed in BL21pLysS bacteria, purified on a GST-column and used to immunize two New Zealand rabbits (Eurogentec, Seraing, Belgium). To generate rabbit antibody against hPCL3S, the full-length hPCL3S isoform was expressed as a GST-fusion protein in BL21pLysS bacteria, purified on a GST-column and used to immunize two New Zealand rabbits (Eurogentec, Seraing, Belgium). However, these antibodies can only detect $\mathrm{hPCL} 3 \mathrm{~S}$ in transient transfection assays but not the endogenous hPCL3S proteins (data not shown).

\section{Transfection and co-immunoprecipitation assays}

HEK293T were maintained in DMEM medium (Gibco) supplemented with $10 \%$ fetal calf serum and non essential amino acids. Cells were transfected in OptiMEM (Gibco) by the PEI method using ExGen 500 (Euromedex), as previously described [23]. Cells were transfected for 6 hours and then were incubated in fresh complete medium. For coimmunoprecipitation assays, $48 \mathrm{H}$ after transfection, cells were rinsed two times in cold PBS and lysed in cold IPH buffer [50mM Tris pH8, $150 \mathrm{mM} \mathrm{NaCl}, 5 \mathrm{mM}$ EDTA, $0.5 \%$ NP-40, protease inhibitor cocktail (Roche)]. Cell lysates were cleared by centrifugation (14000 rpm, $+4^{\circ} \mathrm{C}$ for $30 \mathrm{~min}$ ). The supernatants were incubated overnight with $2 \mu \mathrm{g}$ of antibody. Then, protein A-G Sepharose beads (Amersham Biosciences) were added for $30 \mathrm{~min}$. The beads were washed 3 times with IPH buffer. Proteins were eluted by boiling in Laemmli loading buffer and separated by SDS/PAGE before Western blotting. Western blots were performed as previously described [23]. The secondary antibodies were horseradish peroxidase-linked antibodies raised against rabbit, goat or mouse immunoglobulins (Amersham).

Similarly, the erythromyeloblastoid leukemia cell line K562, which expresses high amounts of hPCL3 mRNAs [17] was used to perform co-immunoprecipitation analyses of endogenous proteins.

\section{Co-immunoprecipitation of chromatin associated proteins.}

Chromatin associated proteins were extracted as previously described with minor modifications [24]. Transiently transfected HEK 293T cells were harvested and lysed for 45 min on a rotator at $4^{\circ} \mathrm{C}$ in buffer A $(50 \mathrm{mM}$ Tris- $\mathrm{HCl} \mathrm{pH} 7,5,1 \mathrm{mM}$ DTT, $20 \mathrm{mM} \mathrm{NaF}, 0,5 \%$ Triton X-100 supplemented with protease inhibitor containing no EDTA (Roche). After centrifugation $10 \mathrm{~min}$ at $1800 \mathrm{~g}$ at $4^{\circ} \mathrm{C}$, pellets were washed twice with buffer A and were resuspended in buffer B and finally treated with $30 \mathrm{U}$ of Micrococcal Nuclease (Fermentas, St Leon Rot, Germany) for $35 \mathrm{~min}$ at $37^{\circ} \mathrm{C}$ under mild agitation. Solubilized proteins were recovered by two rounds of centrifugation $\left(2 \min 5000 \mathrm{rpm}\right.$ at $\left.4^{\circ} \mathrm{C}\right)$. Before immunoprecipitation, the chromatin fraction was adjusted for a final concentration of $\mathrm{NaCl}$ $150 \mathrm{mM}$ and Triton X-100 0,5\%. FLAG-tagged hPCL3S proteins were immunoprecipitated 
with anti-FLAG antibodies coupled to sepharose (SIGMA) for 2 hours on a rotator at $4{ }^{\circ} \mathrm{C}$. Resins were washed 4 times with Tris-buffered saline (TBS), $0,1 \%$ Triton X-100, 0,25\% NP40. Finally, purified proteins were eluted in Laemmli Buffer and subjected to immunoblotting.

\section{Immunofluorescence analyses}

U20S (Human osteosarcoma - ECACC) were maintained in DMEM medium (Gibco) supplemented with 10\% fetal calf serum and non essential amino acids. Cells were cultured on cover slips, transfected by the PEI method as described above and processed at room temperature as previously described [25]. Briefly, they were washed, fixed for $20 \mathrm{~min}$ in cold 3\% paraformaldehyde (PFA), permeabilised in $0.1 \%$ Triton (Tx-100) for 5min, saturated for $30 \mathrm{~min}$ in $300 \mu \mathrm{l}$ of PBS $+10 \%$ goat serum, incubated for $30 \mathrm{~min}$ with the AntiFLAG antibody diluted $1 / 500$ in PBS $+10 \%$ goat serum, incubated in the dark for 30 min with the secondary antibody diluted $1 / 200$ in PBS $+10 \%$ goat serum. Between each stage, they were washed three times for $5 \mathrm{~min}$ in PBS. Nuclei were stained with $10 \mu \mathrm{g} / \mathrm{ml}$ Hoechst 33342 for $1 \mathrm{~min}$. They were then placed inverted on a drop of Immuno Floure Mounting Medium (ICN) on a slide. The slides were stored in the dark at $4^{\circ} \mathrm{C}$ and visualized under fluorescence.

\section{Cell fractionnation experiments}

HEK293T cells were transiently transfected with the pcDNA3-FLAG-hPCL3S and hPCL3L expression vectors. Cytosolic and nuclear fractions were obtained using the Nuclear Extraction kit (Millipore) according to manufacturer's instructions. For Western blot analyses, 50 micrograms of protein from each fraction were loaded and analysed with anti-FLAG antibodies. GAPDH and LAMIN A/C were used as cytoplasmic and nuclear markers.

\section{Analytical gel filtration chromatography}

Cells were lysed in low salt buffer $(10 \mathrm{mM}$ Tris- $\mathrm{HCl} \mathrm{pH} 7.4,25 \mathrm{mM} \mathrm{NaCl}, 2 \mathrm{mM}$ MgOAc, $1 \mathrm{mM}$ DTT, $1 \mathrm{mM}$ EDTA, $0.05 \%$ NP-40 and complete protease inhibitors [Roche]) for $15 \mathrm{~min}$ at $4^{\circ} \mathrm{C}$. Nuclei were pelleted by centrifugation at $4^{\circ} \mathrm{C}$ for $10 \mathrm{~min}$ at $800 \mathrm{~g}$, and lysed in E1A buffer (50 mM Hepes, pH 7.9, 1 mM EGTA, $250 \mathrm{mM} \mathrm{NaCl}, 1 \mathrm{mM}$ DTT, $1 \mathrm{mM}$ EDTA and complete protease inhibitors [Roche]) by gently shaking 2 hours at $4^{\circ} \mathrm{C}$. Nuclear extracts were recovered by centrifugation at $2500 \mathrm{~g}, 10 \mathrm{~min}$ at $4^{\circ} \mathrm{C}$ and clarified by two centrifugations at $10000 \mathrm{~g}$ for $1 \mathrm{~min}$. One $\mathrm{mg}$ of fresh nuclear extract were fractionated on a Superose 6 HR 10/300 GL column (GE Healthcare) equilibrated in $50 \mathrm{mM}$ Tris-HCl pH 7.4, $100 \mathrm{mM} \mathrm{KCl}$. Size exclusion chromatography was performed on a fast protein liquid chromatography (FPLC) system and an $\ddot{A K T A}{ }^{\mathrm{TM}}$ purifier (GE Healthcare). Elution profiles of blue dextran (V0), thyroglobulin $(669 \mathrm{kDa})$, apoferritin $(443 \mathrm{kDa})$, beta-amylase $(200 \mathrm{kDa})$, alcohol dehydrogenase $(150 \mathrm{kDa})$, bovine serum albumin $(66 \mathrm{kDa})$ and carbonic anhydrase (29 $\mathrm{kDa}$, all from Sigma) were used for calibration. All experiments were run at room temperature. Fractions of $0.5 \mathrm{~mL}$ were collected and $25 \mu \mathrm{L}$ aliquots from even-numbered samples were electrophoresed on $4-12 \%$ Bis-Tris gels (Invitrogen) and transferred to nitrocellulose membranes (Schleicher \& Schuell) for Western blotting.

\section{RESULTS}

The two $h P C L 3$ isoforms are expressed at comparable levels in various transformed and normal cell types. 
To accurately measure the expression levels of each hPCL3 isoform, we performed quantitative RT-PCR analyses on total RNAs prepared from various transformed cell lines or from normal human cells including WI38 fibroblasts, hTERT-HME-1 and MCF10A mammary epithelial cells and human umbilical vein endothelial cells (HuVEC). We used sets of primers able to specifically amplify $h P C L 3 L$ and $h P C L 3 S$ isoforms as well as full-length PHF1 (Table 1).

As shown in Figure 2, hPCL3 and PHF1 are differentially expressed in most cell types analyzed. The highest expression levels of both hPCL3 isoforms was observed in the erythromyeloblastoid leukemia cell line K562, as previously shown by RNA dot blot experiments [17] and in the medulloblastoma cell lines, D283 and DAOY. In D283 cells, the variant encoding the small isoform, $h P C L 3 S$ is expressed at a higher level than the transcript encoding the full-length protein, hPCL3L. hPCL3 is more highly expressed than PHF1 in normal endothelial cells (HuVEC) and in mammary epithelial cells (MCF10A and hTERTHME1). However, the inverse situation is observed in normal WI38 fibroblasts which expressed conspicuous levels of PHF1 as compared to a much weaker expression of $h P C L 3$.

Although different total levels of $h P C L 3$ are observed, both $h P C L 3$ isoforms are roughly expressed at similar levels in all cell types examined (Figure 2). By contrast, for PHF1, semi quantitative RT-PCR analyses demonstrated that the PHF1 smaller isoform (O43189-2 : 457 AA) is virtually undetectable in most cell types tested except in the colon carcinoma cell line SW-480 where it is weakly expressed as compared to full length PHF1 (data not shown).

Thus, both $h P C L 3$ isoforms are expressed at comparable levels in various cell types despite major differences in their coding sequences and likely their biochemical properties.

\section{Both hPCL3 isoforms interact with two components of PRC2, EZH2 and EED.}

Drosophila PCL, human PHF1 and human PCL2 interact with PRC2 [10-12, 16, 26]. To demonstrate that hPCL3 also interacts with PRC2 components, we performed coimmunoprecipitation experiments in HEK293T cells using expression vectors encoding each hPCL3 isoform and the enzymatic component of PRC2, the specific H3K27 histone methyltransferase EZH2. Myc-EZH2 was coprecipitated by FLAG-hPCL3L demonstrating that full-length hPCL3 and EZH2 proteins associate in vivo (Figure 3A, right panel, lane 6). Furthermore, Myc-EZH2 was also co-precipitated by FLAG-hPCL3S demonstrating that this smaller isoform is also able to interact with EZH2, albeit less efficiently than the full-length hPCL3L protein (Figure $3 \mathrm{~A}$, right panel, compare lanes 5 and 6).

A similar experiment was conducted with an expression vector for EED (isoform 3) [20]. As shown for EZH2, both hPCL3 isoforms interacted with the core PRC2 component EED. Again the interaction appeared stronger with the full-length hPCL3L protein (Figure $3 \mathrm{~B}$, right panel, compare lanes 5 and 6).

To confirm these interactions between endogenous proteins, we generated rabbit polyclonal antibodies directed against hPCL3L but were unable to obtain antibodies specific for the hPCL3S isoform (see Material and Methods, data not shown). In total cell extracts from K562 erythromyeloblastoid cells expressing high amounts of hPCL3 (Figure 2) [17], EZH2 as well as EED isoforms 1 and 4, were immunoprecipitated by these anti-hPCL3L antibodies but not by normal rabbit immunoglobulins (Figures 3C and 3D).

Taken together, our results demonstrate that both hPCL3 isoforms interact with EZH2 and EED, two components of the PRC2 complex. In addition, the weaker interaction observed in both cases with hPCL3S strongly suggested that domain(s) not present in the smaller isoform may be involved in the interaction with PRC2 components. 


\section{The TUDOR and PHD2 domains, but not the PHD1 domain of hPCL3, are involved in the interaction with EZH2.}

hPCL3L like PHF1 and PCL2 contains an N-terminal TUDOR domain followed by two Zinc-finger-like PHD domains whereas hPCL3S contains a TUDOR domain and only the first PHD1 finger (Figure 1). To identify the hPCL3 domains implicated in the interaction with EZH2, we constructed several deletion mutants. The TUDOR and PHD1 domains were amplified with PCR from the N-terminal and C-terminal portions of hPCL3S and cloned into a pcDNA3FLAG vector. In addition, the TUDOR domain was deleted in the context of the full-length hPCL3L protein (Figure 4A). These constructs were transiently expressed in the absence or in presence of Myc-tagged EZH2 and co-immunoprecipitation experiments were performed. As shown in Figure 4B, the TUDOR domain interacts with EZH2 whereas the Cterminal moiety of hPCL3S containing the PHD1 domain is unable to co-precipitate MycEZH2 (Third panel, lanes 7 and 8). Deletion of the TUDOR domain in the hPCL3L isoform did not abolish the interaction with Myc-EZH2, demonstrating that the TUDOR domain is not the sole domain implicated in this interaction (Figure 4B, lane 10). Indeed, the isolated PHD2 domain which is specific to the hPCL3L isoform is also able to interact with EZH2 (Figure 4B, lane 9). Interestingly, CLUSTAL alignments of hPCL3 proteins from various species demonstrate that their TUDOR and PHD2 domains are well phylogenetically conserved whereas the PHD1 domain is not (data not shown).

The presence of two EZH2 interacting domains (TUDOR and PHD2) in hPCL3L compared with only the TUDOR in hPCL3S might thus explain the stronger interaction observed with hPCL3L (Figures 3A, 3B and 4B). Therefore, the presence of different functional domains in the two hPCL3 isoforms is well correlated with their different biochemical properties, particularly in terms of their interaction with core PRC2 components

\section{The hPCL3L isoform is able to self-associate through the conserved PHD2 domain.}

The N-terminus of ESC, the Drosophila orthologue of EED, mediates its dimerization [27]. To investigate if hPCL3 can also self-associate, we generated HA-tagged hPCL3L and hPCL3S constructs for use in co-immunoprecipitation assays. In transiently transfected HEK293T cells, HA-hPCL3L was coprecipitated by FLAG-hPCL3L demonstrating that the full-length hPCL3L proteins can self-associate in vivo (Figure 5A, Top panel, lane 8). Strikingly, no significant interaction was detected between the HA-tagged small isoform (HA$\mathrm{hPCL3S}$ ) and the FLAG-tagged full length protein (hPCL3L) (Figure 5A, Top panel, lane 7). Thus, despite their co-expression in many cell types (Figure 2) [17], the two hPCL3 isofoms are unlikely to stably hetero-oligomerize in vivo.

To define the hPCL3L functional domain(s) responsible for its self association, we performed co-immunoprecipitation experiments using HA-tagged hPCL3L and the FLAGtagged isolated TUDOR, PHD1 or PHD2 domains (Figure 4). The results of these experiments clearly demonstrated that only the PHD2 finger is able to mediate stable interaction with hPCL3L in vivo (Figure 5B, second panel, lane 8 ).

Thus, our results clearly establish different functional roles for the two PHD fingers of hPCL3L and highlight the importance of the well-conserved PHD2 domain.

\section{The two hPCL3 isoforms display different subcellular localizations.}

In transient expression assays in HEK293T cells, the two hPCL3 isoforms exhibited strikingly different properties as exemplified by their interactions with PRC2 components (Figures 3 and 4) and the self-association of hPCL3L mediated by its unique PHD2 finger (Figure 5). To gain insights on the properties of these hPCL3 proteins, we decided to analyze their subcellular localization. To that end, FLAG-tagged hPCL3L and hPCL3S expression vectors were transiently transfected into U2OS cells. By immunofluorescence analyses, the 
two hPCL3 isoforms exhibited distinct subcellular localization. Indeed, FLAG-hPCL3L proteins were shown to be exclusively nuclear (Figure 6A, top row). By contrast, FLAGhPCL3S proteins were detected in the cytoplasm as well as in the nucleus (Figure 6A, bottom row). To confirm these results using a different technique, we performed cell fractionation experiments of transiently transfected HEK293T cells. The cytosolic and nuclear fractions were prepared and aliquots were analyzed by Western blotting with the monoclonal antiFLAG antibodies or with anti-GAPDH and anti-LAMIN antibodies as controls for cytosolic and nuclear proteins respectively. The results clearly demonstrated that hPCL3L is almost exclusively found in the nucleus with a faint presence in the cytosolic fraction (Figure 6B, top panel, lanes 3 and 6). By contrast, hPCL3S is found in both fractions with a majority in the cytoplasm (Figure 6B, Top panel, lanes 2 and 5)

Thus, the hPCL3L and hPCL3S proteins have overlapping but distinct subcellular localization patterns. Together with their distinct biochemical properties, our results taken as a whole strongly suggest that these two proteins likely participate in different complexes with specific properties.

\section{The two hPCL3 isoforms are present in two different EZH2 containing complexes.}

As a first step towards the identification of complexes containing hPCL3L and hPCL3S, we fractionated nuclear extracts of HEK293T cells transiently expressing TAPtagged versions of hPCL3L or hPCL3S by gel filtration chromatography on a Superose $6 \mathrm{HR}$ 10/300 GL column to separate protein complexes of different sizes. The separated fractions were analysed by Western blot analyses with a peroxydase anti peroxydase (PAP) soluble complex antibody that recognizes the protein A moiety of the TAP tag in order to identify hPCL3 isoform-containing fractions. The results of these fractionation experiments shown in Figure 7A demonstrated that the two hPCL3 isoforms are found in two complexes of different molecular weights. hPCL3L is found in a high molecular weight complex with an estimated size of roughly $2000 \mathrm{KDa}$ which could be the PCL-PRC2 complex identified in previous studies [12]. By contrast, hPCL3S is also found into a multiprotein complex, albeit of much lower molecular weight. Size-exclusion chromatography experiments performed with nuclear extracts derived from TAP-tagged EZH2 expressing cells revealed that EZH2 elutes in the same molecular weight fractions as hPCL3L and hPCL3S. The same results were obtained when these fractionation experiments were performed in HeLa or U2OS cells (data not shown). Although these experiments might not be viewed as definitive, we have demonstrated that endogenous EZH2 and EED can be co-immunoprecipitated with hPCL3L (Figures 3C and 3D). Unfortunately, due to the unavailability of highly sensitive anti-hPCL3S antibodies, the co-immunoprecipitation of endogenous hPCL3S proteins with EZH2 and EED could not be addressed. Nevertheless, in transient transfection assays, we have shown that hPCL3S interacts with EZH2 and EED, albeit less efficiently than hPCL3L (Figures 3C and 3D).

To build upon these results, we next analyzed the co-immunoprecipitation of endogenous EZH2 proteins after transient transfection of pcDNA3-FLAG-hPCL3S, an experimental condition mimicking our TAP-TAG assay. However, since most of the overexpressed FLAG-hPCL3S protein is found in the cytoplasm (Figure 6), we used a recently published fractionation protocol giving access to the chromatin-associated protein fraction [24]. As shown in Figure 7B, chromatin-associated FLAG-hPCL3S proteins can efficiently co-immunoprecipitate endogenous chromatin-bound EZH2 proteins.

Therefore, these gel fractionation experiments considered together with all of the coimmunoprecipitation assays (Figure 3, 4, 5 and 7B) raise the possibility that EZH2 could be part of a least two different protein complexes, one containing the short isoform of hPLC3, and the other containing the long isoform. 


\section{DISCUSSION}

In this report, we studied $h P C L 3$, one of the three human paralogues of the Drosophila $P C L$ gene. Due to alternative splicing mechanisms in its coding exon 5, hPCL3 encodes two different isoforms, hPCL3L and hPCL3S, containing various combinations of functional domains (Figure 1). The PHD finger originally characterized as a protein-protein interaction domain is involved in many biochemical functions, notably methyl-lysine binding [28, 29]. The TUDOR domain initially characterized in RNA-binding proteins is now also considered to be a domain interacting with methylated proteins, including histones $[29,30]$ We have demonstrated that hPCL3L interacts with EZH2, as shown for PHF1 and PCL2 in previous studies $[12,16]$ through its TUDOR and PHD2 finger domains but not its PHD1 finger.

Co-immunoprecipitation analyses of Drosophila embryonic extracts demonstrated that $\mathrm{E}(\mathrm{Z})$ interacts with PCL in vivo but the domains involved are strikingly different [26]. Indeed, both PHD fingers appeared important for this interaction, as shown by directed two-hybrid experiments and by in vitro point mutagenesis which have highlighted conserved residues in the PHD2 Loop1 [26, 31, 32]. The NMR structure of the TUDOR domain from Drosophila PCL demonstrates that its TUDOR domain contains an atypical incomplete aromatic cage, unlikely to interact with methylated arginine or lysine residues [33]. By contrast, the three human PCL orthologs exhibit a complete aromatic cage suggesting that they might bind methylated lysines [33]. Thus, even though the interaction between PCL and $E(Z)$ that is essential for PcG-mediated transcriptional repression is conserved in their human homologues, the precise molecular mechanisms involved might be slightly different.

We have also shown that hPCL3L is able to self-associate in vivo. ESC and its human homologue EED can also dimerize [27], but to the best of our knowledge, this property has never been ascribed to any Polycomb-like protein. The interaction of hPCL3L with EZH2 as well as its self-association in vivo both relies on the PDH2 finger. Given the strong conservation of the PHD2 domains between hPCL3 proteins (data not shown) as well as between the various PCL paralogues, it is tempting to speculate that self-association might be a general property shared by all PCL family members. Concerning the hPCL3 PHD1 domain, which is not evolutionarily well conserved by contrast with the PHD2 finger (data not shown), its function still remains elusive but its role in the interaction between PCL and $E(Z)$ in Drosophila [26] seems to have been lost in mammals.

During evolution, the repertoire of $\mathrm{PcG}$ proteins has been greatly extended and diversified to accommodate the increasing complexity of heritable gene silencing mechanisms in multicellular organisms [3, 7, 34]. For each PcG protein in Drosophila several paralogues with specialized functions and different expression patterns are present in mammals. This holds true both for the PRC1 complex and for different subsets of Polycomb repressive complexes (PRC2, PRC3 and PRC4) which exhibit differential histone substrate specificities [35] and fulfill non-redundant and complementary roles [36, 37]. Similarly, the single Polycomb-like (PCL) gene in Drosophila has three paralogues in human with distinct patterns of expression [11, 12, 16, 17] (Figure 2A). Their coding sequence harbors an N-terminal functional module consisting of a TUDOR, a PHD1 and a PHD2 finger followed by an extended domain of homology with PCL. The strong conservation of these domains with the notable exception of PHD1 suggests that they could fulfill similar functions at least in PcGmediated transcriptional repression. Their C-terminal ends are by contrast highly divergent except for a C-terminal Chromo-like domain. It would be interesting to define if these specific C-terminal ends can be engaged in different interactions with other PcG components, thus specifying subsets of complexes with other chromatin components or even with other nuclear 
proteins. For example, PHF1, but neither PCL2 nor PCL3, is involved in the response to DNA double-strand breaks (DSBs) and their repair [38]. Their recruitment to DSBs is $\mathrm{Ku} 70 / \mathrm{Ku} 80$ dependent and implies a requirement for both the TUDOR domain and a small fragment of the specific C-terminal end (AA 340-431), overlapping the NLS signals [38]. Thus, this expansion and diversification of the $\mathrm{PcG}$ gene together with distinct expression patterns should permit the formation of many different complexes able to exquisitely regulate the myriad of PcG-targets genes in all tissues of a multicellular organism and perhaps also perform other functions, as recently demonstrated for PHF1 in DNA damage response.

Most of the proteins or complexes involved in chromatin transactions contain several so-called effector domains able to engage multiple interactions with specific histone modifications or binding-partners [39, 40]. Therefore, the hPCL3 isoforms might have significantly different functions in view of the partially functional module in the small isoform, hPCL3S. As a first step to define the specific functions of each hPCL3 isoform, we demonstrated that they exhibit different sub-cellular localization and belong to different high molecular weight complexes, containing at least EZH2 (Figures 6 and 7). To gain more insight into the precise physiological functions of these complexes, a future challenge would be to define by proteomic analyses which proteins besides EZH2 and presumably other members of PRC2 complexes are associated with hPCL3L and more importantly with hPCL3S. In addition, Chromatin immunoprecipitation followed by sequencing (ChIP-seq) [41] would define the subsets of PRC2 targets bound respectively by hPCL3L and/or hPCL3S and would allow their comparison with the target-genes bound by PHF1 and hPCL2 [42].

All these studies would help to better define the functional roles of both hPCL3 isoforms, most notably during tumorigenesis.

\section{AUTHOR CONTRIBUTION}

Gaylord Boulay and Claire Rosnoblet performed the experiments and analyzed the results. Cateline Guérardel contributed several new reagents. Pierre-Olivier Angrand and Dominique Leprince conceived the project and analyzed the results. Dominique Leprince wrote the paper with assistance from all authors.

\section{DISCLOSURE OF POTENTIAL CONFLICTS OF INTEREST}

No potential conflicts of interest were disclosed.

\section{ACKNOWLEDGEMENTS}

We thank Drs Stéphane Ansieau, Thomas Jenuwein, Achim Leutz and Kristian Helin for monoclonal antibodies and expression vectors. We thank Dr Etienne Lelievre for the HuVEC cells. We are indebted to Dr Brian R Rood for critical reading of the manuscript.

\section{FUNDING}

This work was supported by funds from CNRS, the PASTEUR Institute, the Ligue Nationale contre le Cancer (Comité Interrégional du Septentrion), the Fondation pour la recherché Médicale (Comité du Nord) and the Association pour la Recherche contre le Cancer [ARC 3983 and ARC 1081] to DL. Gaylord BOULAY was supported by fellowships from the CNRS/Région Nord-Pas de Calais and from the Association pour la Recherche contre le Cancer (ARC). The work in Pierre-Olivier Angrand's laboratory was supported by the CNRS, l'Université Lille Nord de France, and by the Ministère de la Recherche et de l'Enseignement 
B Biochemical Journal Immediate Publication. Published on 10 Dec 2010 as manuscript BJ20100944

Supérieur, the Région Nord-Pas de Calais and the European Regional Developmental Funds trough the "Contrat de Projets Etat-Région (CPER) 2007-2013". 


\section{REFERENCES}

1 Schwartz, Y. B. and Pirrotta, V. (2008) Polycomb complexes and epigenetic states. Curr. Opin. Cell Biol. 20, 266-273

2 Bracken, A. P. and Helin, K. (2009) Polycomb group proteins: navigators of lineage pathways led astray in cancer. Nat. Rev. Cancer 9, 773-784

3 Morey, L. and Helin, K. Polycomb group protein-mediated repression of transcription. Trends Biochem. Sci.

4 Schuettengruber, B. and Cavalli, G. (2009) Recruitment of polycomb group complexes and their role in the dynamic regulation of cell fate choice. Development 136, 3531-3542

5 Pasini, D., Cloos, P. A., Walfridsson, J., Olsson, L., Bukowski, J. P., Johansen, J. V., Bak, M., Tommerup, N., Rappsilber, J. and Helin, K. JARID2 regulates binding of the Polycomb repressive complex 2 to target genes in ES cells. Nature 464, 306-310

6 Li, G., Margueron, R., Ku, M., Chambon, P., Bernstein, B. E. and Reinberg, D. Jarid2 and PRC2, partners in regulating gene expression. Genes Dev. 24, 368-380

7 Simon, J. A. and Kingston, R. E. (2009) Mechanisms of polycomb gene silencing: knowns and unknowns. Nat. Rev. Mol. Cell Biol. 10, 697-708

8 Cao, R. and Zhang, Y. (2004) SUZ12 is required for both the histone methyltransferase activity and the silencing function of the EED-EZH2 complex. Mol. Cell 15, 57-67

9 Tie, F., Prasad-Sinha, J., Birve, A., Rasmuson-Lestander, A. and Harte, P. J. (2003) A 1-megadalton $\mathrm{ESC} / \mathrm{E}(\mathrm{Z})$ complex from Drosophila that contains polycomblike and RPD3. Mol. Cell Biol. 23, 3352-3362

10 Nekrasov, M., Klymenko, T., Fraterman, S., Papp, B., Oktaba, K., Kocher, T., Cohen, A., Stunnenberg, H. G., Wilm, M. and Muller, J. (2007) Pcl-PRC2 is needed to generate high levels of H3-K27 trimethylation at Polycomb target genes. Embo J. 26, 4078-4088

11 Cao, R., Wang, H., He, J., Erdjument-Bromage, H., Tempst, P. and Zhang, Y. (2008) Role of hPHF1 in H3K27 methylation and Hox gene silencing. Mol Cell Biol 28, 1862-1872

12 Sarma, K., Margueron, R., Ivanov, A., Pirrotta, V. and Reinberg, D. (2008) Ezh2 requires PHF1 to efficiently catalyze H3 lysine 27 trimethylation in vivo. Mol. Cell Biol. 28, 2718-2731

13 Coulson, M., Robert, S., Eyre, H. J. and Saint, R. (1998) The identification and localization of a human gene with sequence similarity to Polycomblike of Drosophila melanogaster. Genomics 48, 381-383

14 Kawakami, S., Mitsunaga, K., Kikuti, Y. Y., Ando, A., Inoko, H., Yamamura, K. and Abe, K. (1998) Tctex3, related to Drosophila polycomblike, is expressed in male germ cells and mapped to the mouse t-complex. Mamm Genome 9, 874-880

15 Inouye, C., Remondelli, P., Karin, M. and Elledge, S. (1994) Isolation of a cDNA encoding a metal response element binding protein using a novel expression cloning procedure: the one hybrid system. DNA Cell Biol. 13, 731-742

16 Walker, E., Chang, W. Y., Hunkapiller, J., Cagney, G., Garcha, K., Torchia, J., Krogan, N. J., Reiter, J. F. and Stanford, W. L. Polycomb-like 2 associates with PRC2 and regulates transcriptional networks during mouse embryonic stem cell self-renewal and differentiation. Cell Stem Cell 6, 153-166

17 Wang, S., Robertson, G. P. and Zhu, J. (2004) A novel human homologue of Drosophila polycomblike gene is up-regulated in multiple cancers. Gene 343, 69-78 
18 Ho-Pun-Cheung, A., Bascoul-Mollevi, C., Assenat, E., Boissiere-Michot, F., Bibeau, F., Cellier, D., Ychou, M. and Lopez-Crapez, E. (2009) Reverse transcriptionquantitative polymerase chain reaction: description of a RIN-based algorithm for accurate data normalization. BMC Mol. Biol. 10, 31

19 Laible, G., Wolf, A., Dorn, R., Reuter, G., Nislow, C., Lebersorger, A., Popkin, D., Pillus, L. and Jenuwein, T. (1997) Mammalian homologues of the Polycomb-group gene Enhancer of zeste mediate gene silencing in Drosophila heterochromatin and at S. cerevisiae telomeres. Embo J. 16, 3219-3232

20 Bracken, A. P., Pasini, D., Capra, M., Prosperini, E., Colli, E. and Helin, K. (2003) EZH2 is downstream of the pRB-E2F pathway, essential for proliferation and amplified in cancer. Embo J. 22, 5323-5335

21 Pasini, D., Bracken, A. P., Jensen, M. R., Lazzerini Denchi, E. and Helin, K. (2004) Suz12 is essential for mouse development and for EZH2 histone methyltransferase activity. Embo J. 23, 4061-4071

22 Souza, P. P., Volkel, P., Trinel, D., Vandamme, J., Rosnoblet, C., Heliot, L. and Angrand, P. O. (2009) The histone methyltransferase SUV420H2 and Heterochromatin Proteins HP1 interact but show different dynamic behaviours. BMC Cell Biol. 10, 41

23 Stankovic-Valentin, N., Deltour, S., Seeler, J., Pinte, S., Vergoten, G., Guerardel, C., Dejean, A. and Leprince, D. (2007) An acetylation/deacetylation-SUMOylation switch through a phylogenetically conserved psiKXEP motif in the tumor suppressor HIC1 regulates transcriptional repression activity. Mol. Cell Biol. 27, 2661-2675

24 Van Dessel, N., Beke, L., Gornemann, J., Minnebo, N., Beullens, M., Tanuma, N., Shima, H., Van Eynde, A. and Bollen, M. The phosphatase interactor NIPP1 regulates the occupancy of the histone methyltransferase EZH2 at Polycomb targets. Nucleic Acids Res. 2010 July 29 [Epub ahead of print]

25 Deltour, S., Pinte, S., Guerardel, C., Wasylyk, B. and Leprince, D. (2002) The human candidate tumor suppressor gene $\mathrm{HICl}$ recruits $\mathrm{CtBP}$ through a degenerate GLDLSKK motif. Mol. Cell Biol. 22, 4890-4901

26 O'Connell, S., Wang, L., Robert, S., Jones, C. A., Saint, R. and Jones, R. S. (2001) Polycomblike PHD fingers mediate conserved interaction with enhancer of zeste protein. J. Biol. Chem. 276, 43065-43073

27 Tie, F., Siebold, A. P. and Harte, P. J. (2005) The N-terminus of Drosophila ESC mediates its phosphorylation and dimerization. Biochem. Biophys. Res. Commun. 332, 622-632

28 Mellor, J. (2006) It takes a PHD to read the histone code. Cell 126, 22-24

29 Adams-Cioaba, M. A. and Min, J. (2009) Structure and function of histone methylation binding proteins. Biochem. Cell Biol. 87, 93-105

30 Ponting, C. P. (1997) Tudor domains in proteins that interact with RNA. Trends Biochem. Sci. 22, 51-52

31 Bienz, M. (2006) The PHD finger, a nuclear protein-interaction domain. Trends Biochem. Sci. 31, 35-40

32 Townsley, F. M., Thompson, B. and Bienz, M. (2004) Pygopus residues required for its binding to Legless are critical for transcription and development. J. Biol. Chem. $279,5177-5183$

33 Friberg, A., Oddone, A., Klymenko, T., Muller, J. and Sattler, M. Structure of an atypical Tudor domain in the Drosophila Polycomblike protein. Protein Sci. 19, 19061916

34 Whitcomb, S. J., Basu, A., Allis, C. D. and Bernstein, E. (2007) Polycomb Group proteins: an evolutionary perspective. Trends Genet. 23, 494-502 
35 Kuzmichev, A., Margueron, R., Vaquero, A., Preissner, T. S., Scher, M., Kirmizis, A., Ouyang, X., Brockdorff, N., Abate-Shen, C., Farnham, P. and Reinberg, D. (2005) Composition and histone substrates of polycomb repressive group complexes change during cellular differentiation. Proc. Natl. Acad. Sci. U S A 102, 1859-1864

36 Margueron, R., Li, G., Sarma, K., Blais, A., Zavadil, J., Woodcock, C. L., Dynlacht, B. D. and Reinberg, D. (2008) Ezh1 and Ezh2 maintain repressive chromatin through different mechanisms. Mol. Cell 32, 503-518

37 Shen, X., Liu, Y., Hsu, Y. J., Fujiwara, Y., Kim, J., Mao, X., Yuan, G. C. and Orkin, S. H. (2008) EZH1 mediates methylation on histone H3 lysine 27 and complements EZH2 in maintaining stem cell identity and executing pluripotency. Mol. Cell 32, 491502

38 Hong, Z., Jiang, J., Lan, L., Nakajima, S., Kanno, S., Koseki, H. and Yasui, A. (2008) A polycomb group protein, PHF1, is involved in the response to DNA double-strand breaks in human cell. Nucleic Acids Res. 36, 2939-2947

39 Ruthenburg, A. J., Li, H., Patel, D. J. and Allis, C. D. (2007) Multivalent engagement of chromatin modifications by linked binding modules. Nat. Rev. Mol. Cell Biol. 8, 983-994

40 Taverna, S. D., Li, H., Ruthenburg, A. J., Allis, C. D. and Patel, D. J. (2007) How chromatin-binding modules interpret histone modifications: lessons from professional pocket pickers. Nat. Struct. Mol. Biol. 14, 1025-1040

41 Park, P. J. (2009) ChIP-seq: advantages and challenges of a maturing technology. Nat. Rev. Genet. 10, 669-680

42 Maertens, G. N., El Messaoudi-Aubert, S., Racek, T., Stock, J. K., Nicholls, J., Rodriguez-Niedenfuhr, M., Gil, J. and Peters, G. (2009) Several distinct polycomb complexes regulate and co-localize on the INK4a tumor suppressor locus. PLoS One 4, e6380

43 Wang, S., He, F., Xiong, W., Gu, S., Liu, H., Zhang, T., Yu, X. and Chen, Y. (2007) Polycomblike-2-deficient mice exhibit normal left-right asymmetry. Dev. Dyn. 236, 853-861

\section{FIGURE LEGENDS}

Figure 1. Schematic drawing of the Polycomb-like (PCL) paralogs in human.

The sequences for hPCL3L (also called PHF19) (Q5T6S3 : 580 AA), hPCL3S (Q5T6S3-2: 207 AA), PHF1 (O43189: 567 AA) and hPCL2 (Q9Y483 : 593 AA) were all derived from Expasy/SwissProt. The conserved TUDOR, PHD1 (Plant Homeodomain) and PHD2 domains are indicated $[12,17,26,43]$. For hPCL3L, the PCL extended homology domain (EH), a Cterminal Chromo-like domain (C) are indicated. Two predicted nuclear localization signals (NLS) are shown as black ovals [17].

Figure 2. Expression of the hPCL3 and PHF1 transcript variants in various cell lines. Quantitative expression of PHF1 and of the two hPCL3 isoforms in various normal or transformed cells. Transcript levels were measured by quantitative RT-PCR analyses. Results are normalized to $18 \mathrm{~S}$ and are presented as means +/- standard deviations from two independent experiments in triplicate.

Figure 3. The two hPCL3 isoforms interact with the PRC2 components EZH2 and EED. A) Association of hPCL3L and hPCL3S with EZH2. HEK293T cells were transiently transfected for $48 \mathrm{H}$ with the indicated expression plasmids as well as with the empty 
pcDNA3-FLAG vector as control. Whole cells extracts were prepared in IPH buffer and incubated with anti-FLAG antibodies (Right panel: IP FLAG (hPCL3), lanes 1-6) and immunoblotted (WB) with polyclonal antibodies against Myc to detect EZH2 coimmunoprecipitation. The membrane was then stripped and re-probed with anti-FLAG monoclonal antibodies to ascertain the presence of hPCL3L or hPCL3S. $2 \%$ of each lysate were directly resolved by SDS-PAGE and immunoblotted with the indicated antibodies (Left panel: Input, lanes 1-6).

B) Association of hPCL3L and hPCL3S with EED3. A similar experiment was performed with an expression vector for EED3. To detect EED, we used the AA19 monoclonal antibody (kind gift of K. Helin). The arrowhead indicates the heavy chains of the anti-FLAG monoclonal antibody used in each lane to immunoprecipitate the FLAG-tagged constructs. The presence of a faint amount of EED in lane 4 presumably corresponds to non-specific binding of EED on the beads during the co-immunoprecipitation step.

C) In vivo, endogenous hPCL3L interacts with EZH2. K562 cells were lysed with IPH buffer and $2 \%$ of the lysates were kept as Input (Left panel). Equal amounts of lysates were then immunoprecipitated with normal rabbit immunoglobulins (IgG) or with the rabbit antihPCL3L antibodies (hPCL3L). The immunoprecipitates were analyzed by immunoblot with the mouse anti-EZH2 monoclonal antibody (top panel). The asterisk refers to a non-specific band. The membrane was then incubated with the anti-hPCL3 polyclonal antibodies as control (bottom panel).

D) In vivo, endogenous hPCL3L interacts with another component of the PCR2 complex EED. A similar experiment was conducted in K562 cells, except that the immunonoprecipitates were first analyzed by immunoblot with the mouse anti-EED monoclonal antibody. The EED isoforms detected in the Input or co-immunoprecipitated with hPCL3L are numbered as previously described by Kuzmichev et al. [35]. The arrowhead corresponds to the heavy chains of the rabbit immunoglobulins.

Figure 4. The TUDOR and PHD2 domains of hPCL3L, but not its PHD1 domain, interact with EZH2.

A) Schematic representation of the hPCL3L and hPCL3S isoforms and deletion mutants used.

B) Association of EZH2 with hPCL3 is dependent on the TUDOR and PHD2 domains. HEK293T cells were transiently transfected with the indicated expression plasmids as well as with the empty pcDNA3-FLAG vector as a control for $48 \mathrm{H}$. Whole cells extracts were prepared in IPH buffer and incubated with anti-FLAG antibodies (Top panels: IP FLAG (hPCL3), lanes 1-10) and immunoblotted (WB) with anti-FLAG monoclonal antibodies to verify the presence of $\mathrm{hPCL} 3 \mathrm{~L}$ or its deletion mutants in the immunoprecipitates and with antibodies against the Myc epitope to detect EZH2 co-immunoprecipitation. 2\% of each lysate was directly resolved by SDS-PAGE and immunoblotted with antibodies against Myc to ascertain the presence of EZH2 (Bottom panel: Input, lanes 1-10). In the top panel, the arrowhead indicates the heavy chains of the anti-FLAG monoclonal antibody used in each lane to immunoprecipitate the FLAG-tagged constructs.

Figure 5. The PHD2 domain of hPCL3L is implicated in its self-association.

A) hPCL3L can self-associate but cannot heterodimerize with hPCL3S. HEK293T cells were transiently transfected with the indicated combination of FLAG-and HA-tagged versions of $\mathrm{hPCL} 3 \mathrm{~L}$ or hPCL3S isoforms as well as with the empty pcDNA3-FLAG vector as a control. Whole cells extracts were prepared in IPH buffer and incubated with anti-HA antibodies (IP: HA, lanes 5-8) and immunoblotted (WB) with anti-FLAG antibodies to detect coimmunoprecipitation of hPCL3L (Top Right Panel). The blot was then stripped and probed with anti-HA to verify the presence of hPCL3L and hPCL3S in the relevant 
immunoprecipitates (Bottom Right Panel). 2\% of each lysate was directly resolved by SDSPAGE and successively immunoblotted with anti-FLAG and anti-HA antibodies (Input, Left Panels, lanes 1-4).

B) The PHD2 domain of hPCL3L is implicated in its self-association. A similar experiment was performed with the HA-tagged hPCL3L isoform and the FLAG-tagged isolated domain as well as the empty pcDNA3-FLAG vector as a control. * refers to a non-specific band detected in the input by the anti-HA antibodies.

Figure 6. Distinct subnuclear localization of FLAG-tagged hPCL3L and hPCL3S proteins.

A) Immunofluorescence analyses. U2OS cells transiently transfected with expression vectors for the FLAG-tagged hPCL3L and hPCL3S isoforms, used in the co-immunoprecipitation experiments, were fixed with paraformaldehyde and analyzed by conventional immunofluorescence microscopy using the anti-FLAG monoclonal antibody. Hoechst staining labels nuclei. The merging of the two images is shown in the right column.

B) Cell fractionation experiments. HEK293T cells transiently transfected with expression vectors for the FLAG-tagged hPCL3L and hPCL3S isoforms or with the empty pcDNA3FLAG vector as control were lysed. Cytoplasmic and nuclear fractions prepared with the Nuclear extraction Kit (Millipore) were resolved by SDS-PAGE and immunoblotted with anti-FLAG antibodies (Top Panel) to detect the hPCL3 isoforms. Anti-GAPDH and AntiLAMIN A/C antibodies were used as controls respectively for detection of cytoplasmic and nuclear proteins.

Figure 7. The two hPCL3 isoforms are present in two different complexes.

A) Gel filtration analyses. Nuclear extracts from HEK293T cells transiently expressing TAPtagged hPCL3S, hPCL3L or EZH2 as indicated were subjected to Superose 6 gel filtration. Fractions were analyzed by Western blotting using a peroxidase anti-peroxidase (PAP) soluble complex antibody (Sigma P1291) to reveal the protein A moiety of the TAP tag.

B) Co-immunoprecipitation analyses of chromatin associated proteins. HEK293T cells transiently transfected with the expression vector for FLAG-tagged hPCL3S or with the empty pcDNA3-FLAG vector as a control were lysed. The chromatin associated fractions were incubated with anti-FLAG antibodies and immunoblotted (WB) with anti-EZH2 antibodies to detect co-immunoprecipitation with exogenous FLAG-hPCL3S (Top Right panel [IP: FLAG], lanes 3 and 4). The blot was then stripped and probed with anti-FLAG to verify the presence of hPCL3S in the relevant immunoprecipitates (Bottom Right Panel [IP: FLAG], lanes 3 and 4 ). $2 \%$ of each nuclear fraction was directly resolved by SDS-PAGE and immunoblotted with the same antibodies ([Input], lanes 1 and 2). A shorter exposure of the Input lanes with the EZH2 antibodies is shown on the left to see the lower non-specific band (shown by an asterisk) as well as the upper EZH2 band. 
mRNA levels

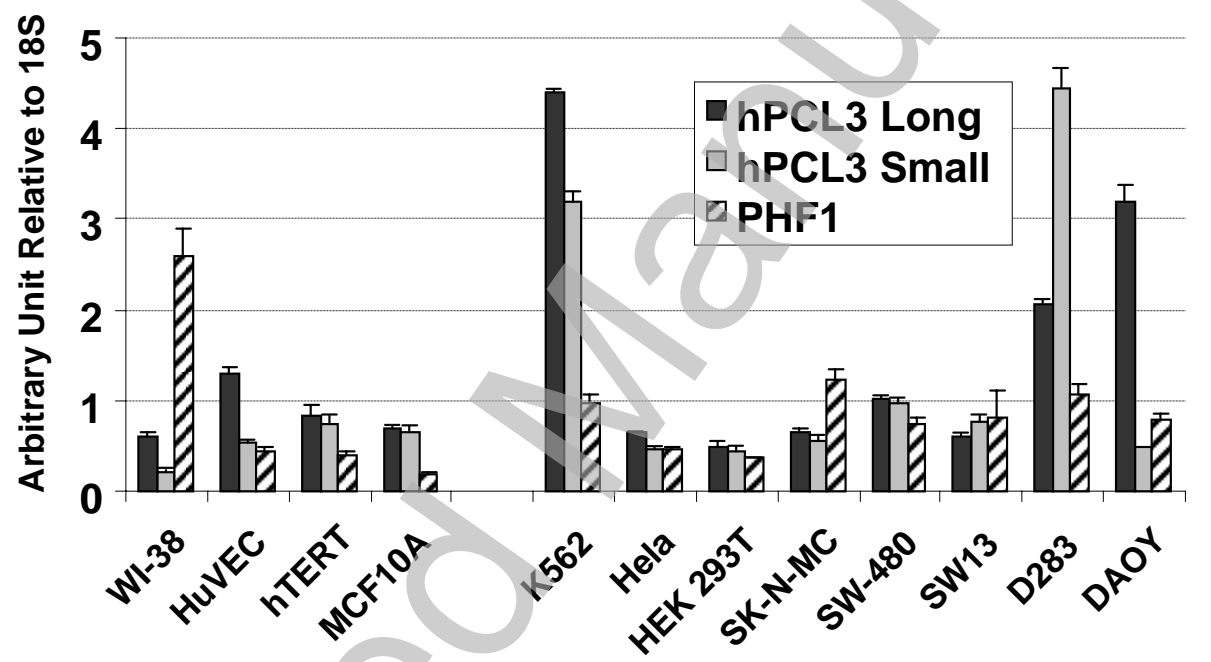

Normal Cells

Transformed Cells

Boulay et al., Figure 2 
A

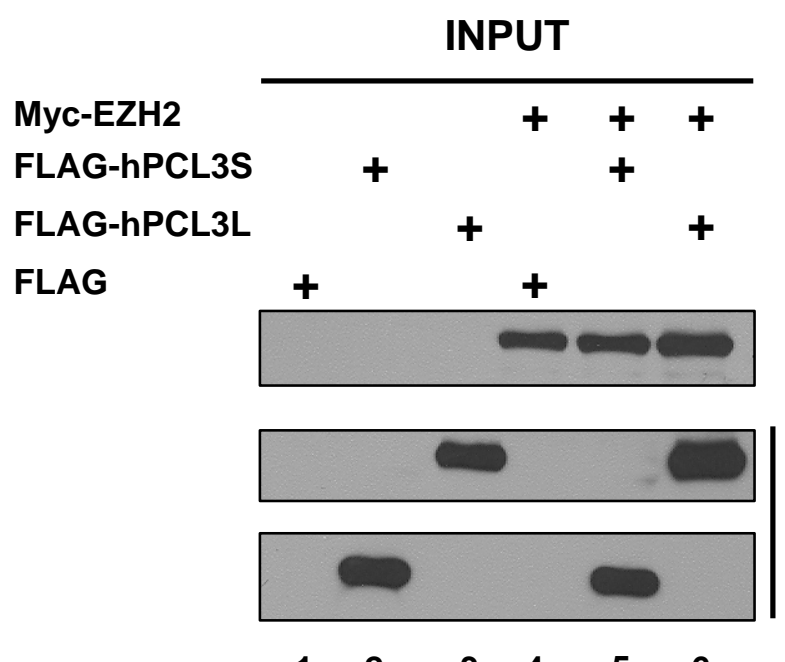

IP: FLAG(hPCL3)
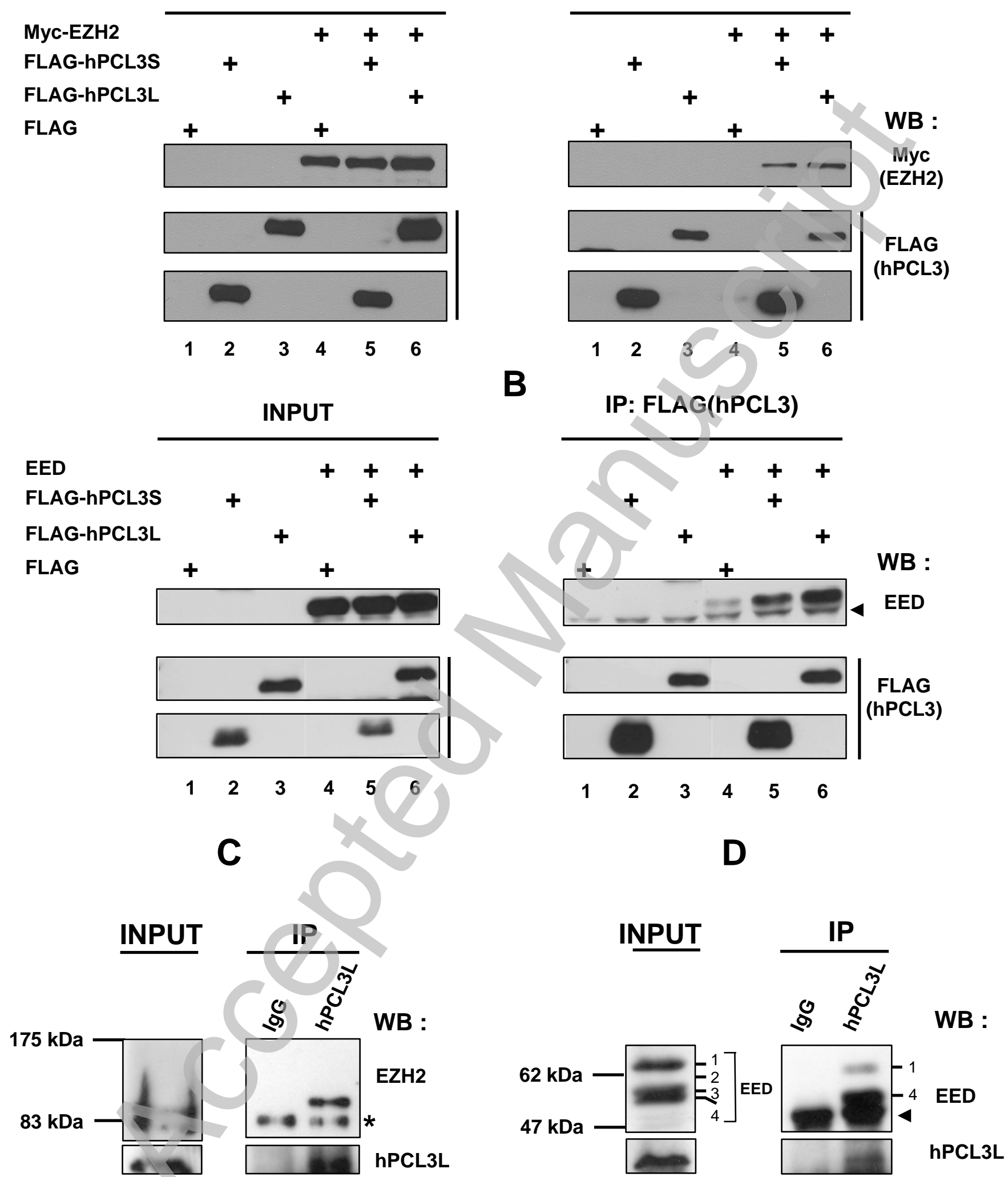

Boulay et al., Figure 3, Revised (Panel D) 
A
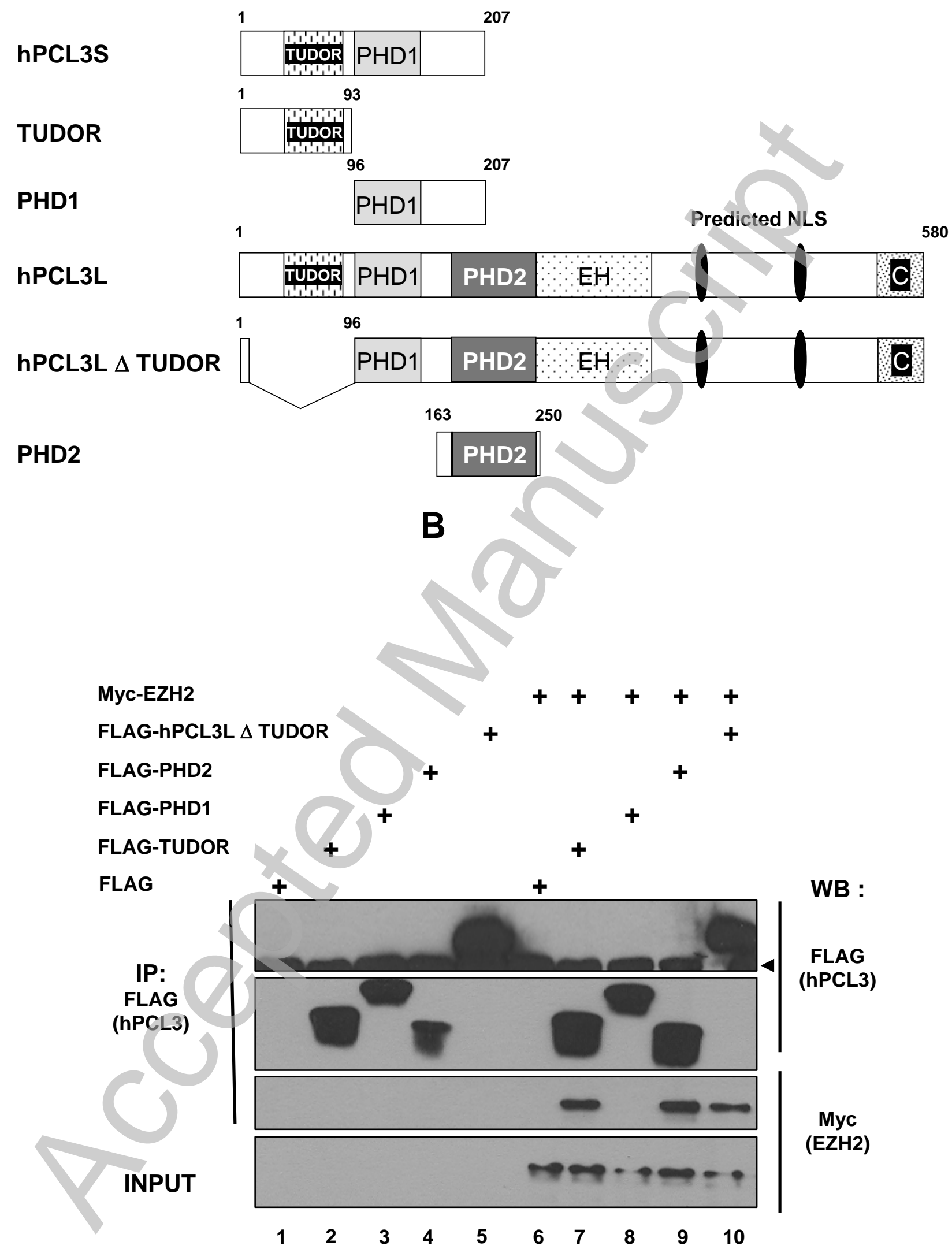

Boulay et al., Figure 4 
A
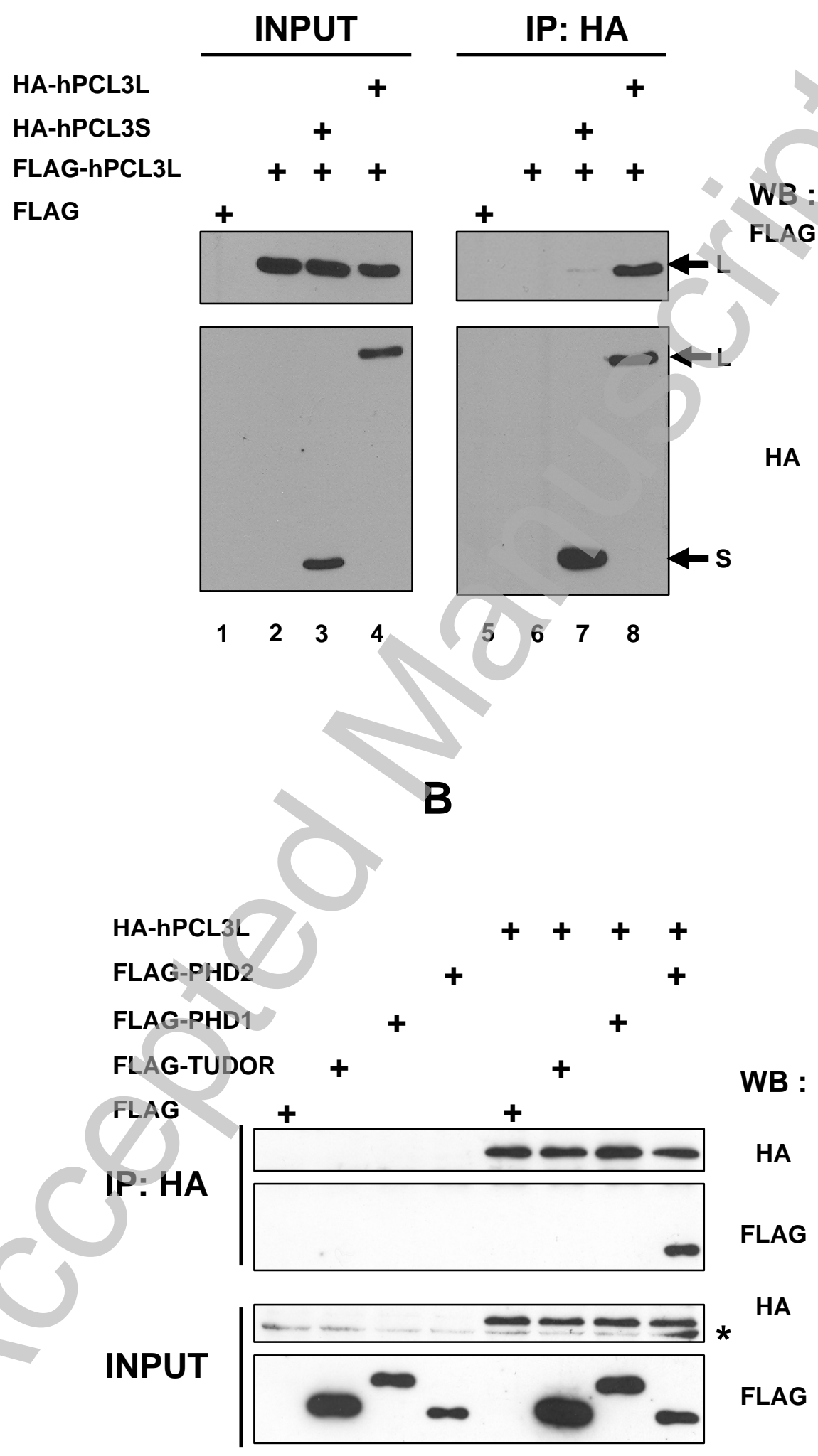

$\begin{array}{llllllll}1 & 2 & 3 & 4 & 5 & 6 & 7 & 8\end{array}$

Boulay et al., Figure 5 


\section{A}

Hoechst

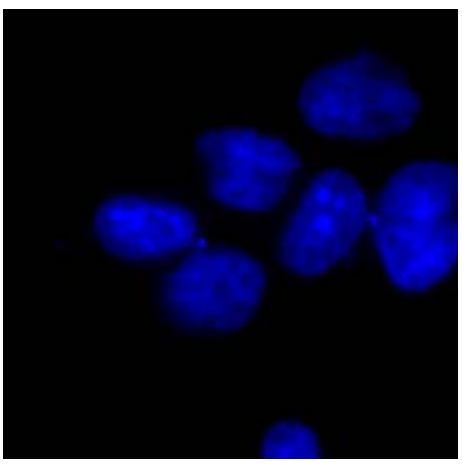

FLAGhPCL3L

FLAGhPCL3S
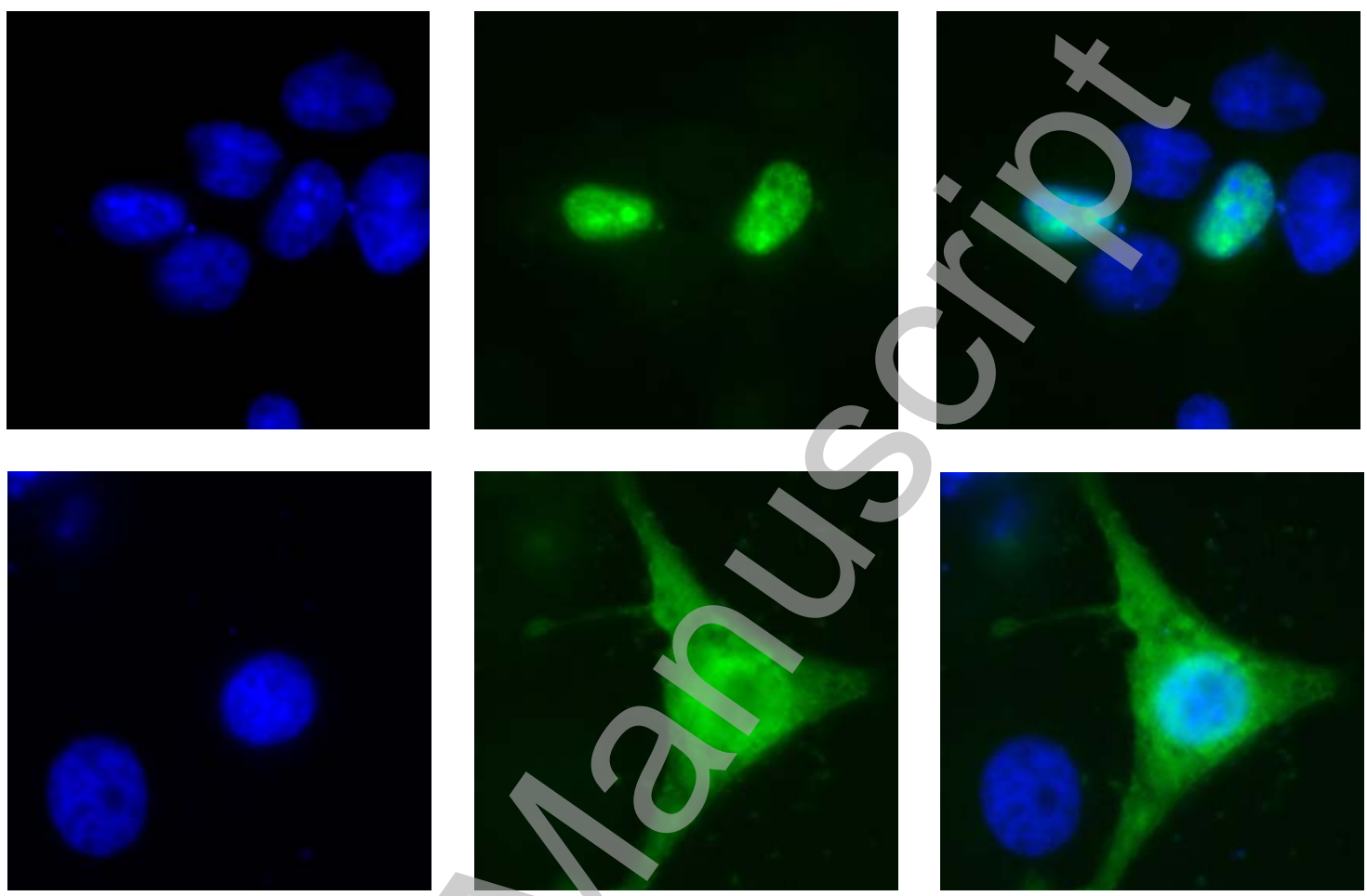

B

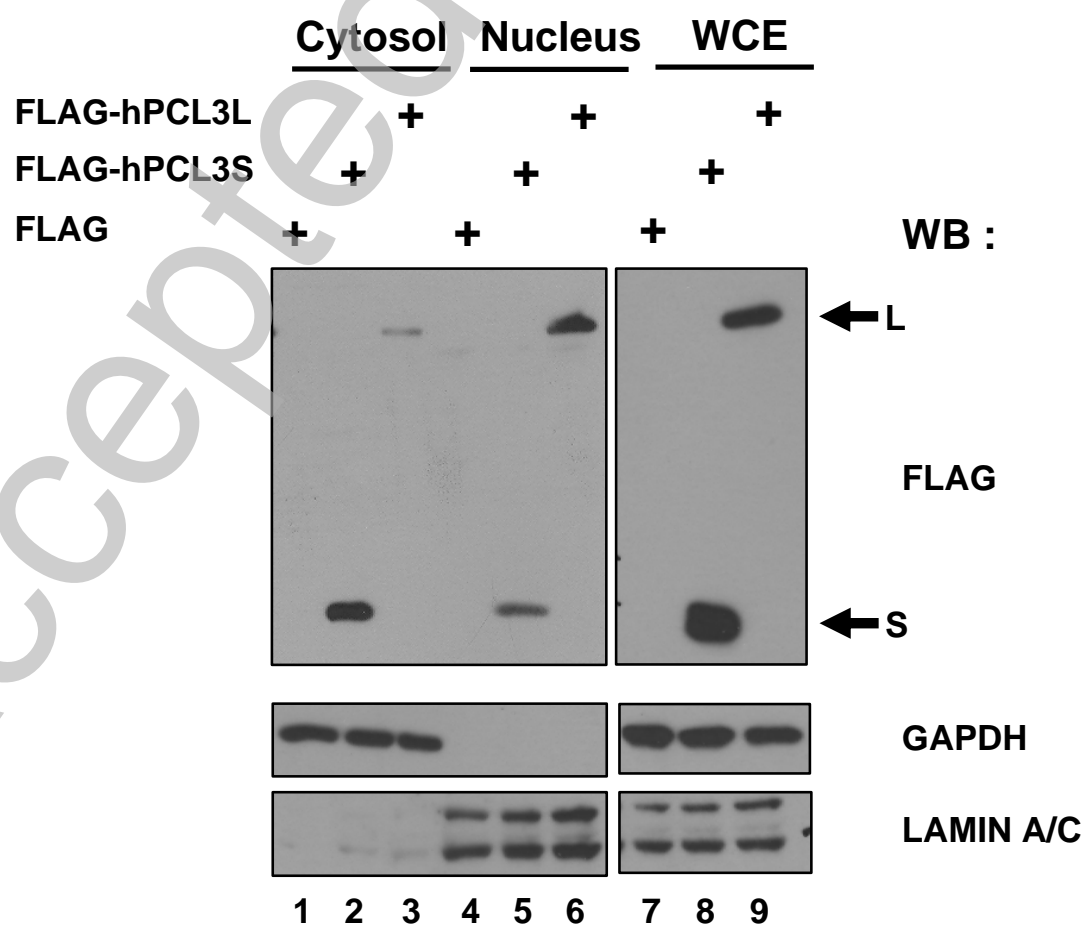

Boulay et al., Figure 6 Revised (Panel A) 


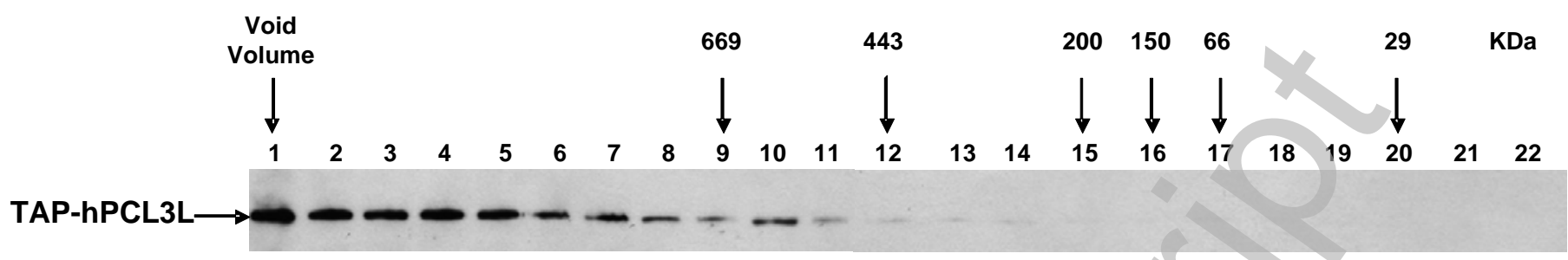

TAP-hPCL3S $\longrightarrow--$

TAP-EZH2

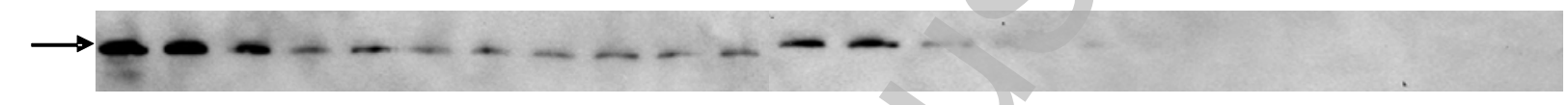

B
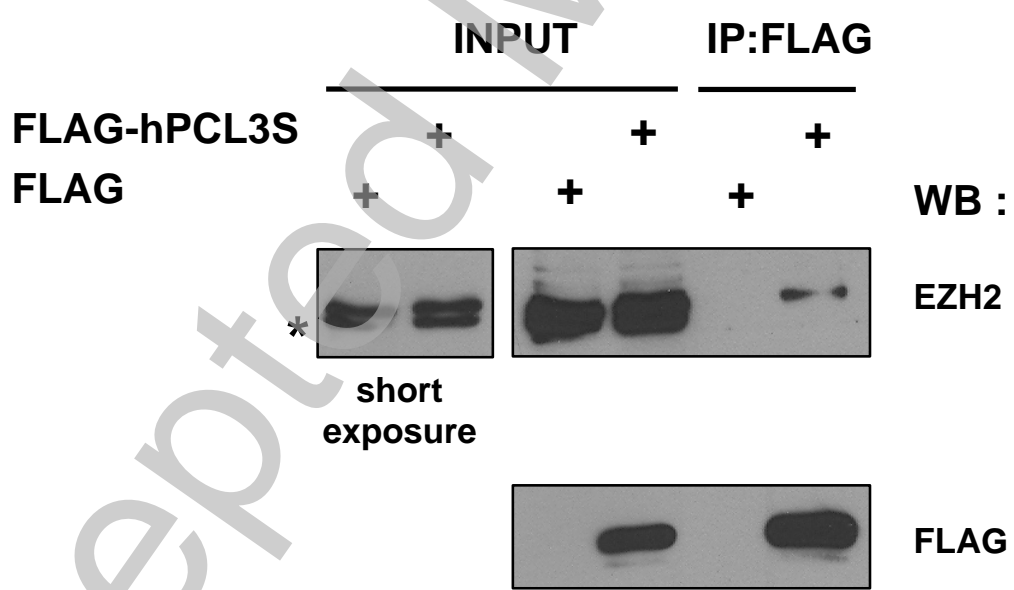

FLAG

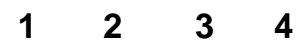

Boulay et al., Figure 7 Revised 


\begin{tabular}{|c|c|c|c|c|}
\hline Gene & sense & Sequence & amplicon size & Reference \\
\hline $\begin{array}{l}\text { hPCL3L } \\
\text { hPCL3L }\end{array}$ & $\begin{array}{l}\text { for } \\
\text { rev }\end{array}$ & $\begin{array}{l}\text { GTTTGGAGACCGGTTTTACCT } \\
\text { CTTGCTCTGTACCCCCAGATTATA }\end{array}$ & $130 \mathrm{bp}$ & This study \\
\hline $\begin{array}{l}\text { PHF1 } \\
\text { PHF1 }\end{array}$ & $\begin{array}{l}\text { for } \\
\text { rev }\end{array}$ & $\begin{array}{l}\text { TTACTGTTACTGTGGTGGCC } \\
\text { GGTGATACAGGACAAGATGG }\end{array}$ & $224 \mathrm{bp}$ & Hong et al 2008 \\
\hline $\begin{array}{l}\text { hPCL3S } \\
\text { hPCL3S } \\
18 S \\
18 S\end{array}$ & $\begin{array}{l}\text { for } \\
\text { rev } \\
\text { for } \\
\text { rev }\end{array}$ & $\begin{array}{l}\text { AGCGCCTCTGCCACTGTC } \\
\text { CCCGACACCAAACCCATCTC } \\
\text { GGCGCCCCCTCGATGCTCTTAG } \\
\text { GCTCGGGCCTGCTTTGAACACTCT }\end{array}$ & $91 \mathrm{bp}$ & $\begin{array}{l}\text { This study } \\
\text { Ho et al, } 2009\end{array}$ \\
\hline
\end{tabular}

\section{Boulay et al. Table 1}

Licenced copy. Copying is not permitted, except with prior permission and as allowed by law. (C) 2010 The Authors Journal compilation (c) 2010 Portland Press Limited 